\title{
Relationship Between Umbilical Cord Essential Fatty Acid Content and the Quality of General Movements of Healthy Term Infants at 3 Months
}

\author{
HYLCO BOUWSTRA, DA JANNEKE DIJCK-BROUWER, TAMÁS DECSI, GÜNTHER BOEHM, E. RUDY BOERSMA, \\ FRITS AJ MUSKIET, AND MIJNA HADDERS-ALGRA
}

\begin{abstract}
Departments of Neurology [H.B., M.H.], Pathology and Laboratory Medicine [J.D., F.M.], and Department of Pediatrics/Obstetrics and Gynecology [E.B.], University Hospital Groningen, 9700 RB, Groningen, The Netherlands; Department of Pediatrics [T.D.], University of Pécs, H-7624 Pécs, Hungary; Numico Research Germany [G.B.], D-61381 Friedrichsdorf, Germany
\end{abstract}

\begin{abstract}
Prenatal essential fatty acid (EFA) status might be an important factor in the development of the central nervous system (CNS). The aim of the present study was to evaluate the relationship between the fatty acid compositions of the umbilical blood vessels at birth, used as a proxy of prenatal EFA status, and quality of general movements (GMs) at 3 mo. Umbilical artery and vein fatty acid compositions were investigated in a mixed group of breastfed infants and infants fed with formula with or without long-chain polyunsaturated fatty acid (LCPUFA) supplementation. At the age of $3 \mathrm{mo}$, video assessment of the quality of GMs was performed to evaluate neurologic condition. The quality of GMs was scored by assessing the degree of variation, complexity, and fluency. Outcomes were classified as normal-optimal, normal suboptimal, mildly abnormal, and definitely abnormal movements. Information on potential confounders, including the type of postnatal feeding, was collected prospectively. Associations between fatty acid status at birth and quality of GMs were investigated, and multinomial logistic regression analyses were carried out. None of the infants showed definitely abnormal movements. Infants with mildly abnormal GMs had a lower EFA index, lower arachidonic acid (AA) content, higher total n-9 fatty acid, and higher total monounsaturated fatty acid (MUFA) content in the umbilical artery compared with infants with normal GMs. Multivariate analyses confirmed these findings. We conclude that mildly abnormal GMs are associated with a less favorable EFA status in the umbilical artery. (Pediatr Res 59: 717-722, 2006)
\end{abstract}

$\mathrm{L}^{\mathrm{c}}$ CPUFAs are abundantly present in the CNS of infants (1). Their accumulation in the brain occurs, especially during the last trimester of gestation and during early postnatal life $(1,2)$, a process that is affected by nutrition $(3,4)$. It is conceivable that dietary supplementation of LCPUFAs enhances incorporation of LCPUFAs into the membranes of the CNS and possibly improves the neurologic condition of the young child. At present, there is increasing evidence of a beneficial effect of LCPUFA supplementation on visual function and psychomotor development in preterm and term infants (5-7). No consistent evidence has been provided of a positive effect

Received August 24, 2005; accepted December 14, 2005.

Correspondence: Mijna Hadders-Algra, M.D., Ph.D., Developmental Neurology, University Hospital Groningen, CMC-IV, 3rd floor, Hanzeplein 1, 9700 RB Groningen, The Netherlands; e-mail: M.Hadders-Algra@med.umcg.nl

The study was financially supported by Numico Research BV.

DOI: 10.1203/01.pdr.0000215013.19164.57 of LCPUFA supplementation on developmental outcome at 1 to $3 \mathrm{y}$, and no data are available on the effect of LCPUFA supplementation on neurobehavioral development beyond the age of 3 y $(8-10)$.

Less is known about the effect of the infant's neonatal fatty acid status on neurodevelopmental outcome. A recent study by our own group indicated that a lower neonatal status of docosahexaenoic acid [(DHA), a member of the n-3 fatty acid series], AA (a member of the $n-6$ fatty acids), EFA in the umbilical vein is associated with a less favorable neurologic condition on postnatal days 10 to 14 (11). Helland et al. (12) reported that supplementation with cod liver oil (rich in n-3 fatty acids) during pregnancy and lactation resulted in higher levels of n-3 fatty acids in blood plasma at birth, which were associated with more mature electroencephalography (EEG) scores on the second day of life. Neonatal fatty acid status was not related to EEG maturity at 3 mo. Follow-up at 4 y indicated that neonatal DHA in plasma at birth was not related to intelligence (13). A negative correlation was found between neonatal Mead (20:3n-9) and Osbond (22:5n-6) acids, which represent lower EFA status and intelligence at 4 y (13). Malcolm et al. (14), in a study in which pregnant women received supplementation with either fish oil capsules rich in DHA or placebo capsules, did not find a relationship between the infant's DHA status in red blood cells and plasma at birth and latencies to visually evoked potentials recorded to flash stimuli shortly after birth and at the ages of $10 \mathrm{wk}$ and $6 \mathrm{mo}$. However, they did find a relationship between neonatal DHA status and latencies to visually evoked potentials recorded to pattern-reversal stimuli at $10 \mathrm{wk}$ and $6 \mathrm{mo}$. Two other studies found no relationship between neonatal LCPUFA status and cognitive function at 4 and $7 \mathrm{y}$ of age $(15,16)$.

Taken together, it is as yet unclear whether neonatal LCPUFA status affects neurodevelopmental outcome, and if so, which LCPUFA plays a prominent role. To detect the

Abbreviations: AA, arachidonic acid; DHA, docosahexaenoic acid; EFA, essential fatty acid; GMs, general movements; LCPUFA, long-chain polyunsaturated fatty acid; MUFA, monounsaturated fatty acid; OOS, obstetric optimality score 
possible subtle effects of neonatal fatty acid status on neurologic condition, sensitive evaluation instruments are required. Previous studies by our group indicated that the assessment of the quality of GMs is a sensitive tool for evaluating the effect of nutritional status on neurologic condition $(6,17)$. GMs are spontaneous movements involving all parts of the body. They arise early in fetal life and persist until 3-4 mo after term age when goal-directed behavior emerges. Normal GMs are characterized by variation, complexity, and fluency. These characteristics disappear when movements become abnormal. The presence of definitely abnormal GMs at 2-4 mo predicts the development of cerebral palsy with a high accuracy (18-20). The presence of mildly abnormal GMs at $2-4$ mo is associated with an increase in the risk of the development of minor neurologic dysfunction, attention problems, and aggressive behavior at school age (19-21).

In previous studies, we evaluated the effect of LCPUFA supplementation of infant formula and that of the influence of duration of breastfeeding on the quality of GMs $(6,17)$. None of the participating healthy term infants had definitely abnormal GMs. We found that LCPUFA supplementation was associated with a reduction of mildly abnormal GMs and that breastfed infants showed better movement quality when they had received human milk for more than $6 \mathrm{wk}$.

The present paper is based on the groups of infants who participated in the LCPUFA supplementation study. We addressed the question whether the fatty acid composition of the umbilical blood vessels at birth of infants who showed mildly abnormal GMs at 3 mo differed from that of infants with normal GMs. The problem was tackled with multivariate statistics to be able to take into account the role of type of postnatal feeding and other confounders.

\section{SUBJECTS AND METHODS}

Subjects. This study is part of a double-blind, randomized, controlled trial investigating the effect of LCPUFA supplementation on neurodevelopment of healthy term infants. The study has been described in detail in Bouwstra et al. (6). Mother-infant pairs were recruited during pregnancy checkup visits at various locations in and near Groningen. Final enrollment in the study occurred in the neonatal period, at which time parents provided written informed consent. All infants were born at 37-42 wk of gestation, had a native West European origin, and were born between February 1997 and October 1999. Excluded from the study were children with a congenital disorder interfering with adequate functioning in daily life, children from multiple births, children whose mother did not master the Dutch language or had significant illness or disability, and adopted and fostered children. The study population consisted of 474 infants. There were three study groups: two randomized formula groups and one group of mothers who decided to breastfeed their infants $(n=159)$. The control formula group $(n=169)$ received commercial formula feeding (Nutrilon Premium; Nutricia, Zoetermeer, the Netherlands) for 6 mo and the LCPUFA-supplemented formula group $(n=146)$ received the same formula enriched with $0.45 \%$ AA and $0.30 \%$ DHA for 2 mo. After 2 mo, the LCPUFA-supplemented group received control formula feeding until the age of $6 \mathrm{mo}$. Breastfeeding was given as long as possible. If breastfed infants required formula feeding as a supplement or when breastfeeding stopped, they received LCPUFAsupplemented formula until 2 mo and control formula from 2 to 6 mo. Parents and examiners were unaware of the type of formula feeding that the infants received. The study was approved by the Ethics Committee of the University Medical Centre Groningen (MEC 95/08/207).

Analysis of fatty acids of the umbilical vessels. Permission to obtain umbilical cord tissue was granted in 317 infants, i.e. in $67 \%$ of the original population (Fig. 1). The umbilical cord was immediately collected after parturition. Details on the collection and processing can be found in Muskiet et al. (22). Seven to $10-\mathrm{cm}$ samples were taken at the most proximal site of

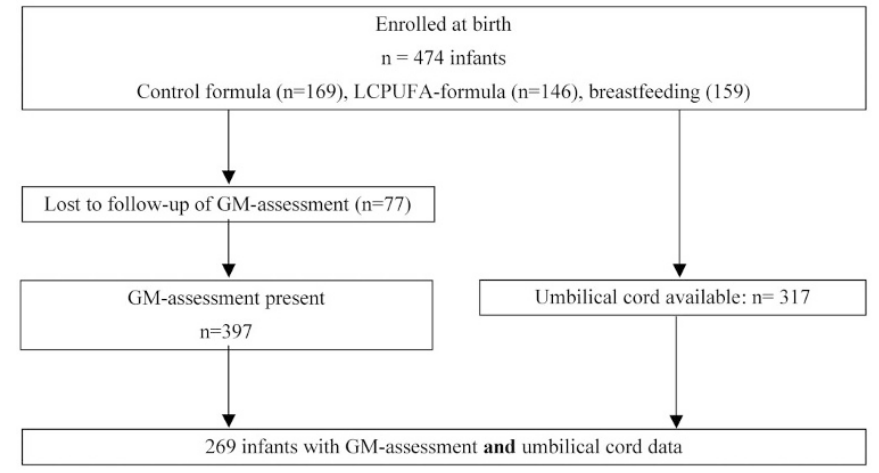

Figure 1. Flow diagram of infants included into the present study.

the placenta and stored in saline at $4^{\circ} \mathrm{C}$ for a maximum duration of $24 \mathrm{~h}$ until further processing for fatty acid analyses according to established methods (22). Fatty acid methyl esters, trans-fatty acids included, were determined by high-resolution capillary gas liquid chromatography as described by DijckBrouwer et al. (11) and Decsi et al. (23). Data were expressed as percentages of weight of fatty acids with chain lengths of 14-24 carbon atoms. EFA status was derived from 20:3n-9 (Mead acid), 20:3n-9/20:4n-6, and the EFA index $(n-3+n-6) /(n-7+n-9)$, while the DHA deficiency index (22:5n-6/22:4n-6) was used to describe DHA status (23).

Neurologic assessment at 3 mo. Follow-up at the age of 3 mo was performed for 269 of the infants for whom information on fatty acid status in the umbilical cord was available (Fig. 1). The major reason that infants were not assessed at 3 mo was an overload of work for the research team. The social and pre- and perinatal backgrounds of infants who were included in the present analyses are shown in Table 1. Social and pre- and perinatal backgrounds of infants included in the present analyses were in general similar to those of the infants who were not included into the analyses because of missing fatty acid samples or missing GM assessment. However, infants not included in the study did have a slightly lower obstetric optimality score (OOS) (mean values: 62 versus $61, p<0.05$ ) and more had fathers who smoked $(51 \%$ versus $41 \%, p<0.05)$. For more details, see section on assessment of potential confounders.

The neurologic assessment consisted of the evaluation of the quality of GMs. The infants' spontaneous motility was videotaped for $15 \mathrm{~min}$ in the home environment. During the recording, the infant was dressed in his or her underwear, and he or she was lying in supine position. Care was taken to only record GMs when the infants were awake, active, and not crying. Investigators who were blinded to the subjects' group assignments analyzed the quality of the videotaped GMs. Movements were classified as normal-optimal, normal-suboptimal, and mildly abnormal. The classification in categories was based on the criteria shown in Table 2. Experienced observers evaluated these criteria, which are the three main characteristics of GMs: (1) GM complexity, denoting the spatial variation of the movements; (2) GM variation, which represents the temporal variation of the movements; (3) GM fluency, which indicates the presence of smooth, subtle, and graceful movements. The interscorer agreement on GM quality is good: $\kappa=0.81$ (24). As mentioned before, none of the infants had definitely abnormal GMs. For the present analyses, the infants with normal-optimal and normal-suboptimal GMs were pooled into one group.

Assessment of potential confounders. At enrollment, detailed and standardized information was collected on the infants' social and pre- and perinatal conditions. For the latter, we used the 74 variables of the OOS, ranging from the parents' socioeconomic status and health condition to the infant's condition immediately after birth. The sum of all items having a value within a predefined optimal range forms the OOS for an infant (25). We used the information obtained from the OOS both at the single-item level where the items were dichotomized into optimal and nonoptimal categories and in the form of the sum of all items of the OOS. Besides collecting information on the parents' level of education and occupation, social condition was also assessed by the HOME inventory (26). Information on the distribution of confounding variables in the groups of infants with normal and mildly abnormal GMs are presented in Table 1 .

Statistics. The analyses focused on the differences in fractions of fatty acid composition of umbilical vessel wall between infants with normal GMs and those with mildly abnormal GMs. First, univariate statistical analyses were performed with the Mann-Whitney test to calculate differences in fatty acid composition in umbilical vein and artery wall between children with normal and mildly abnormal GMs. Next multivariate analyses were carried out by 
Table 1. Social and perinatal characteristics of the infants included in the analyses

\begin{tabular}{|c|c|c|c|c|}
\hline Variables & Total group & Normal GMs & Mildly abnormal GMs & $p$ value* \\
\hline Total no. of children & 269 & 205 & 64 & \\
\hline Male gender $(\%)$ & 54 & 53 & 59 & N.S. \\
\hline Birth weight, mean $\pm \mathrm{SD}(\mathrm{g})$ & $3551 \pm 424$ & $3571 \pm 419$ & $3488 \pm 419$ & N.S. \\
\hline Maternal age $(y)$, mean $\pm \mathrm{SD}$ & $30 \pm 4.3$ & $31 \pm 4.2$ & $30 \pm 4.6$ & N.S. \\
\hline Maternal education: higher education (\%) & 22 & 23 & 19 & N.S. \\
\hline Paternal education: higher education (\%) & 23 & 25 & 18 & N.S. \\
\hline Maternal alcohol consumption during pregnancy (\%) & 14 & 12 & 22 & 0.04 \\
\hline $\mathrm{OOS} \dagger$, mean $\pm \mathrm{SD}$ & $62 \pm 3.7$ & $62 \pm 3.6$ & $62 \pm 4.1$ & N.S. \\
\hline HOME score $\ddagger$, mean \pm SD & $43 \pm 2.1$ & $43 \pm 2.1$ & $43 \pm 2.2$ & N.S. \\
\hline
\end{tabular}

* Difference between infants with normal GMs and those with mildly abnormal GMs.

$\dagger$ The obstetric optimality score consists of 74 variables describing the obstetric condition, ranging from the parents' socioeconomic status and health condition to the infant's condition immediately after birth (31)

$\ddagger$ Home Observation for Measurement of the Environment (HOME) inventory (32).

N.S., not significant.

Table 2. Classification of the quality of GMs

\begin{tabular}{lccc}
\hline \multicolumn{1}{c}{ Classification } & Complexity & Variation & Fluency \\
\hline Normal-optimal GMs & +++ & +++ & + \\
Normal-suboptimal GMs & ++ & ++ & - \\
Mildly abnormal GMs & + & + & - \\
Definitely abnormal GMs & - & - & - \\
\hline
\end{tabular}

GM complexity, spatial variation: The infant actively produces frequent changes in movement direction of the participating body parts. The changes in movement direction are brought about by continuously varying combinations of flexion-extension, abduction-adduction, and endorotation-exorotation of the participating joints.

GM variation, temporal variation: Across time, the infant produces continuously new movement patterns, i.e. the infant has an apparently infinite movement repertoire.

GM fluency, presence of smooth, supple, and graceful movements: Fluency in particular points to the velocity profile of the movements, which is characterized by gradual accelerations and decelerations.

+++ , abundantly present; ++ , sufficiently present; + , present, but insufficiently; -, absent.

means of multinomial logistic regression analyses. This allowed us to elucidate the relationship between fatty acid status at birth and GM quality while correcting for type of postnatal feeding and potential confounders such as the postnatal age of the infant at GM assessment, paternal smoking, and the total OOS. For calculating the effect of postnatal feeding, a dummy variable was created for the four following nutritional groups: LCPUFA formula, control formula, breastfeeding for $\leq 6 \mathrm{wk}$, breastfeeding $>6 \mathrm{wk}$. Nonparametric statistics were used as the large majority of variables were not normally distributed. $p$ Values $<0.05$ were considered significant. Statistical analyses were performed using SPSS 10 (SPSS Inc., Chicago, IL).

\section{RESULTS}

The fatty acid composition of the umbilical veins of infants with mildly abnormal GMs did not differ significantly from that of infants with normal GMs (Fig. 2). However, the fatty acid composition of the umbilical artery did differ between the infants with mildly abnormal GMs and those with normal movements (Table 3). Univariate analyses indicated that the umbilical artery of infants who showed mildly abnormal GMs contained more MUFAs and n-9 fatty acids (especially 18:1n-9, i.e. oleic acid) and contained fewer LCPUFAs, in particular less AA, a lower EFA index, and a higher DHA deficiency index than the artery of infants with normal GMs (Fig. 2). Trans-fatty acid content of the umbilical artery of

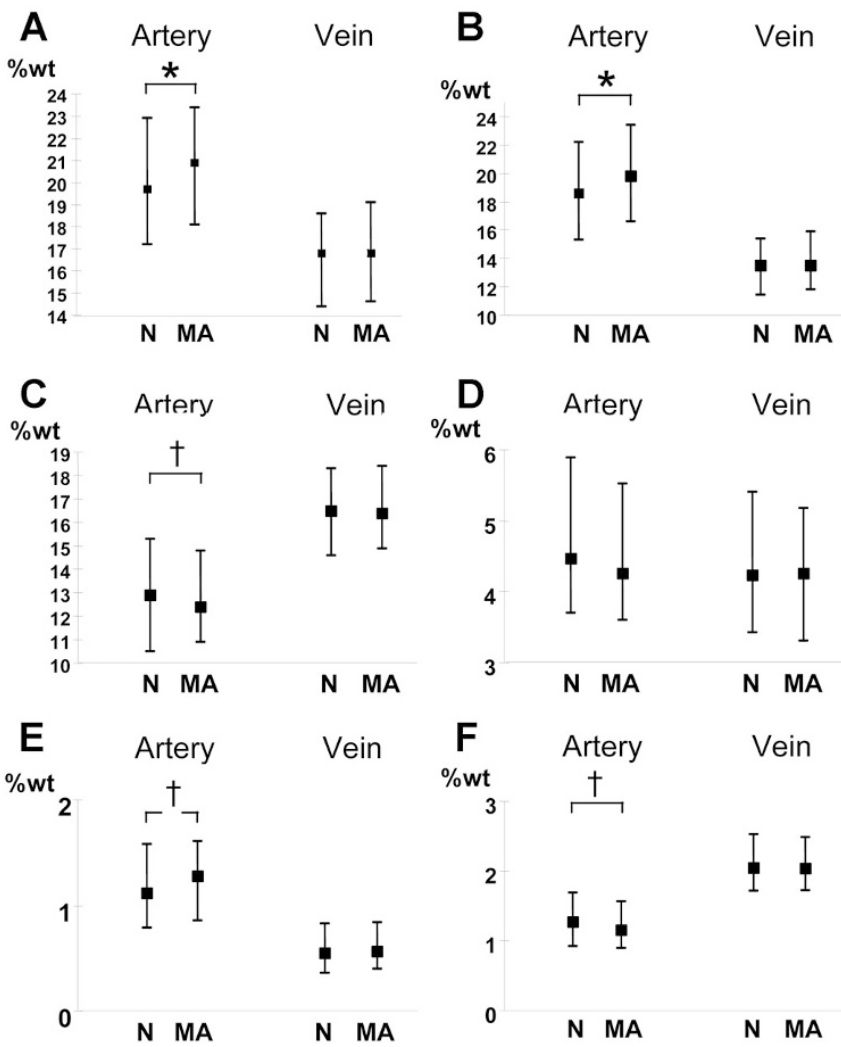

Figure 2. Differences in the fatty acid composition of umbilical cords between infants with normal (N) and mildly abnormal (MA) GMs. (A) Total MUFA, $(B)$ total of n-9, $(C)$ AA, $(D)$ DHA, $(E)$ DHA deficiency index, $(F)$ EFA index. The vertical lines represent the ranges between the 10th and 90th percentiles of values of the percentage of weight; the horizontal bars show the median values. $* p<0.01 ; \dagger p<0.05$.

infants with mildly abnormal GMs did not differ from that of infants with normal GMs. Multivariate analyses confirmed all but one of these relationships: the relationship between DHA deficiency index and GM quality disappeared when correcting for confounders (Table 4). Confounders that contributed consistently and significantly to the risk of showing mildly abnormal GMs were a lower age at GM assessment, the mother not being married during pregnancy, and the condition of the 
Table 3. Fatty acid composition of the umbilical artery wall of infants with normal and mildly abnormal GMs

\begin{tabular}{|c|c|c|c|c|c|c|}
\hline $\begin{array}{l}\text { Fatty acid, } \\
\text { umbilical artery }\end{array}$ & \multicolumn{2}{|c|}{$\begin{array}{l}\text { Infants with normal GMs } \\
\qquad(n=205)\end{array}$} & \multicolumn{2}{|c|}{$\begin{array}{l}\text { Infants with mildly } \\
\text { abnormal GMs } \\
(n=64)\end{array}$} & $\begin{array}{c}\text { Univariate analyses, } \\
\quad p \text { value }\end{array}$ & $\begin{array}{c}\text { Multivariate analyses, } \\
\quad p \text { value }\end{array}$ \\
\hline Total SAFA & 49 & $46-59$ & 49 & $44-53$ & N.S. & N.S. \\
\hline Total MUFA & 20 & $14-26$ & 21 & $17-25$ & 0.003 & 0.003 \\
\hline Total n-9 fatty acids & 19 & $11-26$ & 20 & $15-25$ & 0.002 & 0.001 \\
\hline $20: 3 n-6$ & 2 & $1-3$ & 1 & $0.8-2$ & 0.03 & 0.02 \\
\hline $20: 4 n-6$ & 13 & $9-19$ & 12 & $9-16$ & 0.04 & 0.03 \\
\hline $22: 4 n-6$ & 3 & $2-6$ & 3 & $2-4$ & N.S. & 0.02 \\
\hline $22: 5 n-6$ & 4 & $2-6$ & 4 & $2-5$ & N.S. & N.S. \\
\hline $22: 6 n-3$ & 5 & $1-7$ & 4 & $3-7$ & N.S. & N.S. \\
\hline Total $\Sigma$ n-6 and n-3 & 27 & $19-33$ & 26 & $19-30$ & 0.03 & 0.02 \\
\hline
\end{tabular}

Values are \%wt.

* See Table 4.

SAFA, saturated fatty acids; DHA deficiency index, 22:5n-6/22:4n-6; EFA index, $(n-3+n-6) /(n-7+n-9)$.

Table 4. Results of logistic regression analyses of the contribution of fatty acid status at birth to the occurrence of mildly abnormal GMs, corrected for potential confounders such as postnatal feeding group

\begin{tabular}{lccc}
\hline \multicolumn{1}{c}{ Factors } & $\begin{array}{c}\text { Standardized } \\
\text { coefficients* } \\
(95 \% \text { CI })\end{array}$ & $p$ & $\begin{array}{c}\text { Explained } \\
\text { variance } \\
\text { Cox and Snell }\end{array}$ \\
\hline Umbilical artery & & & \\
Total MUFAs & $1.27(1.09-1.40)$ & 0.003 & $17 \%$ \\
Total n-9 FA & $1.23(1.09-1.39)$ & 0.001 & $24 \%$ \\
18:1n-9 & $1.33(1.10-1.60)$ & 0.006 & $23 \%$ \\
Total LCPUFAs & $0.86(0.74-0.99)$ & 0.03 & $13 \%$ \\
20:3n-6 & $0.33(0.13-0.85)$ & 0.02 & $14 \%$ \\
20:4n-6 & $0.81(0.68-0.98)$ & 0.03 & $13 \%$ \\
$22: 4 n-6$ & $0.50(0.27-0.90)$ & 0.02 & $19 \%$ \\
$22: 5 n-6$ & $1.0(0.62-1.8)$ & N.S. & $17 \%$ \\
$22: 6 n-3$ & $0.74(0.48-1.1)$ & N.S & $18 \%$ \\
Total n-3 and n-6 & $0.87(0.78-0.97)$ & 0.02 & $14 \%$ \\
Total trans-fatty acids & $1.8(0.37-8.9)$ & N.S. & $12 \%$ \\
DHA deficiency index $\dagger$ & $2.0(0.73-5.2)$ & N.S. & $12 \%$ \\
$20: 3 n-9 / 20: 4 n-6$ & $20(1.01-397)$ & 0.048 & $13 \%$ \\
EFA index & $0.16(0.045-0.53)$ & 0.003 & $15 \%$ \\
\hline
\end{tabular}

* A standardized coefficient of $>1$ means higher risk of the occurrence of mildly abnormal GMs; a standardized coefficient $<1$ means a lower risk of the occurrence of mildly abnormal GMs.

$\dagger$ Only significant in the univariate analysis.

perineum, i.e. the presence of either an intact perineum or a total rupture. Having been breastfed for $>6 \mathrm{wk}$ was consistently associated with a lower risk of mildly abnormal GMs. We assume that the association between the condition of the perineum and the quality of GMs was a chance finding.

\section{DISCUSSION}

Our study indicates that mildly abnormal GMs at 3 mo are associated with a lower AA and EFA status of the umbilical artery at birth. The neonatal DHA status was not related to neurologic condition as measured by GM quality, i.e. the association between DHA deficiency index and GM quality was present in the univariate analysis, but disappeared in the multivariate analysis. In addition, we found that mildly abnormal GMs were associated with a higher level of monounsaturated fatty acids and with a higher total concentration of n-9 fatty acids, in particular, of oleic acid, in the umbilical artery at birth. The associations between fatty acid compositions of the umbilical artery remained statistically significant when taking into account important confounders such as type of postnatal feeding, age at investigation, and obstetric and social factors including smoking and maternal alcohol consumption during pregnancy. Univariate analysis indicated that maternal alcohol use during pregnancy was related to the occurrence of mildly abnormal GMs. This association disappeared in the multivariate analysis. No indications were found that maternal alcohol consumption modified the relationships between neonatal fatty acid status and the quality of GMs. It is well-known that prenatal alcohol exposure may affect the condition of the fetal brain (27). However, our data indicated that the effect of prenatal fetal fatty acid status on postnatal neurologic condition is stronger than that of modest prenatal alcohol exposure.

Interestingly, the randomized allocation into the standard formula group or LCPUFA-supplemented formula group during the first 2 mo after birth no longer had an effect on the quality of GMs when neonatal fatty acid status was taken into account (6). This suggests that neurologic condition rather depends on the prenatal essential fatty acid status than on the type of postnatal feeding.

The differences in fatty acid compositions of the umbilical artery between children with normal and mildly abnormal GMs were relatively small. Nevertheless, the standardized coefficients in the multinomial regression analysis indicated that even small differences in fatty acid composition significantly affect neurologic condition at $3 \mathrm{mo}$ and thus might be considered clinically relevant. 
It is interesting to note that we found relationships between GM quality and fatty acid composition in the umbilical artery and not in the umbilical vein. The umbilical vein represents the supply of fatty acids from the placenta and the fat stores of the mother. The umbilical artery fatty acid composition represents the downstream of fatty acids from the fetus that is positively affected by placental supply and fetal synthesis of fatty acids and negatively influenced by fetal extraction. We did not find any differences in umbilical vein fatty acid composition between infants with normal GMs and mildly abnormal GMs. This might imply that an inadequate maternal fatty acid supply was not a determinant of the quality of GMs in this study population. Instead our data suggest that the development of mildly abnormal GMs might be associated particularly with the impaired extraction or increased dilution of AA and EFA driven by fetal metabolism and not by maternal supply. It could be that dilution of EFA and LCPUFAs in the umbilical artery is the result of an increased maternal supply of glucose to the placenta that induces extra de novo fatty acid synthesis from glucose, especially saturated fatty acids and MUFAs in the fetus $(11,28)$. This suggestion fits with our finding that the arteries of infants with mildly abnormal GMs contained relatively more MUFAs.

In general, DHA is considered to be the most important LCPUFA for early brain development (29). However, the evidence of this idea basically stems from supplementation studies carried out during postnatal life (30). In the present study, we found that neonatal AA status, in particular, was related to neurologic outcome. The relationship between the DHA deficiency index of the umbilical artery and GM quality disappeared when the association was corrected for confounders. This could imply that during neonatal life, the supply of AA to the fetus is more critical than the supply of DHA. This hypothesis is supported by the finding that during gestation the accretion rates of $\mathrm{n}-6$ fatty acids in the fetal brain are approximately twice as high as those of n-3 fatty acids (31). After birth, accretion of DHA seems to become more critical because after term age, brain DHA content increases with increasing age, whereas brain AA content remains quite constant (1). Another finding that supports the idea that accretion of AA is more critical than DHA accretion is the lower AA content in the umbilical artery compared with the umbilical vein (median $12.8 \%$ and $16.5 \%$, respectively), whereas less difference existed between DHA content of the umbilical vein and umbilical artery (median $4.4 \%$ and $4.3 \%$, respectively). Also the study of Agostoni et al. (32), which found a significant relationship between early postnatal AA status and psychomotor development at $5 \mathrm{mo}$ in children with phenylketonuria underscores the importance of AA status in early life.

Current data, including the data from this study, indicate that neonatal fatty acid status does not only affect neurologic status at birth $(11,12)$ and maturation of latencies to visually evoked potentials at $10 \mathrm{wk}$ and $6 \mathrm{mo}$ (14), but also the neurologic condition at $3 \mathrm{mo}$. The finding that neonatal fatty acid status, in particular EFA and AA status, affects the prevalence of mildly abnormal GMs might be a finding with clinical relevance because it is known that the presence of mildly abnormal GMs is associated with an increased risk of the development of minor neurologic dysfunction and attention problems at school age (19-21). Until now, however, data on the long-term effects of fatty acid status of the neonate are inconclusive. Three studies have been carried out that were all characterized by high rates of attrition $(13,15,16)$. The two studies, which were based on an observational design, were unable to find a relationship between maternal fatty acid status and cognitive function at school age $(15,16)$. The intervention study of Helland et al. (13) was able to demonstrate a relationship between maternal DHA supplementation and cognition at $4 \mathrm{y}$.

In conclusion, neonatal fatty acid status, in particular lower AA composition and EFA index in the umbilical artery, is associated with a less favorable neurologic condition at 3 mo of age as reflected by the presence of mildly abnormal GMs. Whether neonatal fatty acid status affects long-term neurodevelopmental outcome remains an open question. To answer this question, we need prospective observational and intervention studies with long-term follow-up and little attrition.

\section{REFERENCES}

1. Martínez M, Mougan I 1998 Fatty acid composition of human brain phospholipids during normal development. J Neurochem 71:2528-2533

2. Clandinin MT, Chappell JE, Leong S, Heim T, Swyer PR, Chance GW 1980 Intrauterine fatty acid accretion rates in human brain: implications for fatty acid requirements. Early Hum Dev 4:121-9

3. Farquharson J, Cockburn F, Patrick WA, Jamieson EC, Logan RW 1992 Infant cerebral cortex phospholipid fatty-acid composition and diet. Lancet 340:810-813

4. Farquharson J, Jamieson EC, Abbasi KA, Patrick WJ, Logan RW, Cockburn F 1995 Effect of diet on the fatty acid composition of the major phospholipids of infant cerebral cortex. Arch Dis Child 72:198-203

5. Agostoni C, Trojan S, Bellu R, Riva E, Giovannini M 1995 Neurodevelopmental quotient of healthy term infants at 4 months and feeding practice: the role of long-chain polyunsaturated fatty acids. Pediatr Res 38:262-266

6. Bouwstra H, Dijck-Brouwer DA, Wildeman JA, Tjoonk HM, van der Heide JC, Boersma ER, Muskiet FA, Hadders-Algra M 2003 Long-chain polyunsaturated fatty acids have a positive effect on the quality of general movements of healthy term infants. Am J Clin Nutr 78:313-318

7. Fewtrell MS, Abbott RA, Kennedy K, Singhal A, Morley R, Caine E, Jamieson C, Cockburn F, Lucas A 2004 Randomized, double-blind trial of long-chain polyunsaturated fatty acid supplementation with fish oil and borage oil in preterm infants. J Pediatr 144:471-479

8. Simmer K. Longchain polyunsaturated fatty acid supplementation in infants born at term. Cochrane Database of Systematic Reviews [database online] 2001, issue 4, article no. CD000376. DOI: 10.1002/14651858.CD000376.

9. Bouwstra H, Dijck-Brouwer DA, Boehm G, Boersma ER, Muskiet FA, HaddersAlgra M 2005 Long-chain polyunsaturated fatty acids and neurological developmental outcome at 18 months in healthy term infants. Acta Paediatr 94:26-32

10. Agostoni C, Trojan S, Bellu R, Riva E, Bruzzese MG, Giovannini M 1997 Developmental quotient at 24 months and fatty acid composition of diet in early infancy: a follow up study. Arch Dis Child 76:421-424

11. Dijck-Brouwer DA, Hadders-Algra M, Bouwstra H, Decsi T, Boehm G, Martini IA, Boersma ER, Muskiet FA 2005 Lower fetal status of docosahexaenoic acid, arachidonic acid and essential fatty acids is associated with less favorable neonatal neurological condition. Prostaglandins Leukot Essent Fatty Acids 72:21-28

12. Helland IB, Saugstad OD, Smith L, Saarem K, Solvoll K, Ganes T, Drevon CA 2001 Similar effects on infants of $\omega 3$ and $\omega 6$ fatty acids supplementation to pregnant and lactating women. Pediatrics 8:E82

13. Helland IB, Smith L, Saarem K, Saugstad OD, Drevon CA 2003 Maternal supplementation with very-long-chain $\mathrm{n}-3$ fatty acids during pregnancy and lactation augments children's IQ at 4 years of age. Pediatrics 111:e39-e44

14. Malcolm CA, McCulloch DL, Montgomery C, Shepherd A, Weaver LT 2003 Maternal docosahexaenoic acid supplementation during pregnancy and visual evoked potential development in term infants: a double blind, prospective, randomised trial. Arch Dis Child Fetal Neonatal Ed 88:F383-F390

15. Ghys A, Bakker E, Hornstra G, van den Hout M 2002 Red blood cell and plasma phospholipid arachidonic and docosahexaenoic acid levels at birth and cognitive development at 4 years of age. Early Hum Dev 69:83-90

16. Bakker EC, Ghys AJ, Kester AD, Vles JS, Dubas JS, Blanco CE, Hornstra G 2003 Long-chain polyunsaturated fatty acids at birth and cognitive function at $7 \mathrm{y}$ of age. Eur J Clin Nutr 57:89-95 
17. Bouwstra H, Boersma ER, Boehm G, Dijck-Brouwer DA, Muskiet FA, HaddersAlgra M 2003 Exclusive breastfeeding of healthy term infants for at least 6 weeks improves neurological condition. J Nutr 133:4243-4245

18. Prechtl HF, Einspieler C, Cioni G, Bos AF, Ferrari F, Sontheimer D 1997 An early marker for neurological deficits after perinatal brain lesions. Lancet 349:13611363

19. Hadders-Algra M, Groothuis AM 1999 Quality of general movements in infancy is related to neurological dysfunction, ADHD, and aggressive behaviour. Dev Med Child Neurol 41:381-391

20. Hadders-Algra M, Mavinkurve-Groothuis AM, Groen SE, Stremmelaar EF, Martijn A, Butcher PR 2004 Quality of general movements and the development of minor neurological dysfunction at toddler and school age. Clin Rehabil 18:287-299

21. Groen SE, de Blécourt AC, Postema K, Hadders-Algra M 2005 General movements in early infancy predict neuromotor development at 9-12 years of age. Dev Med Child Neurol 47:731-738

22. Muskiet FA, van Doormaal JJ, Martini IA, Wolthers BG, van der Slik W 1983 Capillary gas chromatographic profiling of total long-chain fatty acids and cholesterol in biological materials. J Chromatogr 278:231-244

23. Decsi T, Boehm G, Tjoonk HM, Molnar S, Dijck-Brouwer DA, Hadders-Algra M, Martini IA, Muskiet FA, Boersma ER 2002 Trans isomeric octadecenoic acids are related inversely to arachidonic acid and DHA and positively related to mead acid in umbilical vessel wall lipids. Lipids 37:959-965

24. Hadders-Algra M 2004 General movements: a window for early identification of children at high risk for developmental disorders. J Pediatr 145:S12-S18
25. Touwen BC, Huisjes HJ, Jurgens-van der Zee AD, Bierman-van Eendenburg ME Smrkovsky M, Olinga AA 1980 Obstetrical condition and neonatal neurological morbidity. An analysis with the help of the optimality concept. Early Hum Dev 4:207-208

26. Bradley RH, Caldwell BM, Brisby J, Magee M, Whiteside L, Rock SL 1992 The HOME inventory: a new scale for families of pre- and early adolescent children with disabilities. Res Dev Disabil 13:313-333

27. Mulder EJ, Morssink LP, van der Schee T, Visser GH 1998 Acute maternal alcohol consumption disrupts behavioral state organization in the near-term fetus. Pediatr Res 44:774-779

28. Widdowson EM 1968 Growth and composition of the fetus and newborn. In: Assali NS Biology of Gestation. Academic Press, New York, pp 1-49

29. Lauritzen L, Hansen HS, Jorgensen MH, Michaelsen KF 2001 The essentiality of long chain n-3 fatty acids in relation to development and function of the brain and retina. Prog Lipid Res 40:1-94

30. Uauy R, Hoffman DR, Mena P, Llanos A, Birch EE 2003 Term infant studies of DHA and ARA supplementation on neurodevelopment: results of randomized controlled trials. J Pediatr 143:S17-S25

31. Clandinin MT, Chappell JE, Leong S, Heim T, Swyer PR, Chance GW 1980 Extrauterine fatty acid accretion in infant brain: implications for fatty acid requirements. Early Hum Dev 4:131-138

32. Agostoni C, Verduci E, Massetto N, Radaelli G, Riva E, Giovannini M 2003 Plasma long-chain polyunsaturated fatty acids and neurodevelopment through the first 12 months of life in phenylketonuria. Dev Med Child Neurol 45:257-261

\section{Erratum}

In the Review Article, "The Ever-Elusive Endothelial Progenitor Cell: Identities, Functions and Clinical Implications," by Chad L. Barber and M. Luisa Iruela-Arispe, appearing in Pediatric Research 2006; 59(Pt2):26R-32R), several of the references cited in Table 1 were in error. The author regrets this error.

Table 1. Summary of in vivo studies on EPCs, markers, and results

\begin{tabular}{|c|c|c|c|c|}
\hline Source of cells & Surface marker/model & Functional readout & Percent incorporation & Reference \\
\hline $\begin{array}{l}\text { PB-MNC (mouse and } \\
\text { rabbit) }\end{array}$ & CD34/flk1, CD45 & Hind limb ischemia & $\begin{array}{l}13.4 \pm 5.7 \% \text { (mouse) or } 9.7 \pm 4.5 \% \\
\quad \text { (rabbit) }\end{array}$ & 1 \\
\hline Canine BM-MNC & CD34, vWF, DiI-Ac-LDL & Incorp. Into Dacron graft & ND & 2 \\
\hline Mouse BM-MNC & Tie2/LacZVEGFR2/LacZ & $\begin{array}{l}\text { Colon cancer, Inductive } \\
\text { ovulation, wound healing, } \\
\text { ischemia }\end{array}$ & Diffuse, not quantified & 5 \\
\hline Mouse BM-MNC & SCL-1/LacZ & Tumor xenograft & $0 \%$ & 28 \\
\hline Mouse BM-MNC & Tie2/LacZ & Soft tissue graded ischemia & $\begin{array}{l}\text { Correlates to level of } \\
\text { ischemia, not quantified }\end{array}$ & 51 \\
\hline Human BM-MNC & CD31, vWF, Y chromosome & $\begin{array}{l}\text { Human sex-mismatched } \\
\text { BMT }\end{array}$ & $2 \%$ & 62 \\
\hline \multicolumn{5}{|c|}{$\begin{array}{l}\text { Cells cultured/manipulated } \\
\text { in vitro before assay }\end{array}$} \\
\hline Human BM-MNC & $\begin{array}{l}\text { CD34-, VE-Cad-, VEGFR2+, } \\
\text { AC133+ }\end{array}$ & $\begin{array}{l}\text { Tumor xenograft/wound } \\
\text { healing }\end{array}$ & $35 \% / 30-45 \%$ & 22 \\
\hline $\operatorname{Lin}(-) \mathrm{BM}-\mathrm{MNC}$ & LentiviralTie2-GFP & Tumor xenograft & $<1 \%$ & 27 \\
\hline Mouse BM-MNC & Tie2/GFP & Tumor xenograft & EC: $1-2 \%$ Monocyte: $4 \%$ & 30 \\
\hline HUVEC/HAEC & Unselected & Murine Tumor xenograft & Not quantified & 72 \\
\hline Sheep PB-MNC & $\begin{array}{l}\text { VEGFR2, Tie2, vWF, CD31, } \\
\text { Dil-Ac-LDL }\end{array}$ & Vessel graft survival & $80 \%$ & 70 \\
\hline
\end{tabular}

PB-MNC, Peripheral Blood-Mononuclear Cell; BM-MNC, Bone Marrow-Mononuclear Cell; ND, not determined; HSC, Hematopoetic Stem Cell; HUVEC, human umbilical vein endothelial cell; HAEC, human aortic endothelial cell; BMT, bone marrow transplantation; lin(-), lineage negative. 